direct contact and organization of the event to the students in my class, a situation the school district has been willing to support. At times my temptation has been to jump into the event ans straighten something out, but this would strip the students of much of the learning from this experience. Fortunately, the students have always done an effective job and, even at a few tense moments, l've maintained as low a profile as possible.

The only real problems we've encountered are the scarity of field trip sites available in a small community and the fact that special class students have to be back to meet their buses at 2:15 p.m.

The positive aspects are a learning experience for our teachers-in-training, the enthusiastic reactions from public school students and teachers, and the support from the local administration in working with the university special education program. A comment from one WSU student sum. marizes it best. "Boy, when I was in school and we took a field trip, we just took a field trip. But when l'm a teacher l'll know how to do it-pre-lessons, the field trip, and follow-up."

\title{
REFERENCES
}

Squires, S. Course outline for Career Development and Vocational Guidance for the Handicapped. Pullman: Washington State University, 1981.

Sandra K. Squires, Department of Counseling and Special Education, University of Nebraska, Omaha, NE 68182.

\section{Geraldine Markel, Ella Bowen, Gregory Kasza, \& Sherry Bell: A State-Wide, Inservice Project for Special Needs Personnel}

There is little doubt that inservice training is a priority issue for those providing career and vocational services to the handicapped (Heller \& Schilit, 1979; Moorman, 1980). Of critical importance also is the manner in which inservice education is approached and the results of such efforts.

The Occupational and Special Education Program within the University of Michigan recently provided a state-wide inservice program for special needs personnel under a grant funded by the State Department of Educa. tion Vocational-Technical Services, Michigan Department of Education. Eight regional 11/2-day workshops served over 900 individuals in vocational education programs for handicapped, disadvantaged, and limited English proficient students in secondary classrooms. The participants included vocational and special education personnel, paraprofessionals, administrators, parents, students, and those in support services such as CETA and Vocational Rehabilitation. 
This article describes the use of a systems approach for planning, implementing, and evaluating the conjoint training project and makes recommendations for future endeavors.

\section{TRAINING DESIGN}

\section{Framework}

Three major themes were basic to the project: collaboration between Occupational and Special Education programs, involvement of personnel in the field (Berman \& McLaughlin, 1976) and an application of systems theory (Brown, 1966; Mockler, 1974; Weiner, 1950). A system was defined as a dynamic and highly interrelated set of elements focused upon the common goal of understanding and explaining the planning, control, and decision-making process. A set of management guidelines was then established to facilitate collaborative efforts between the two separate programs and with professionals within the field.

\section{Goals}

The major goal was to help participants acquire awareness and knowledge-and in some cases leadership strategies - essential for working with handicapped students at secondary and postsecondary levels.

Based on recommendations from the Department of Education, faculty coordinators, and a regional planning committee, objectives were identified which covered three broad areas: (a) information on specific content areas such as bilingual education or specialized materials, $(b)$ awareness of current issues and attiludinal barriers, and (c) opportunities to interact and share with colleagues within various regions.

Although a state-wide needs assessment was conducted, time constraints precluded the use of these results for planning. These data are currently being reported and integrated into other training projects.

\section{IMPLEMENTATION GUIDELINES}

The adoption of a systems model dictated an identification of the project's components and an analysis of tasks related to each part. Four phases and related guidelines and activities were specified for the project. These were (a) input-selecting content area and planning activities; (b) process-engaging in administrative and training activities; (c) feedbackusing information on performance to maintain or modify subsequent training efforts; and (o) output-identifying the outcomes and impact of training. 


\section{Input Phase}

This phase incorporated planning for the entire series of workshops and preparation for individual workshops.

\section{Project design}

The grant required presentation of eight workshops: six regional $11 / 2$-day workshops open to all personnel on a first come, first served basis and two similar workshops limited according to roles (administrators and commu. nity college personnel).

\section{Planning committees}

Given the commitment to participant involvement, regional input was sought by establishing committees composed of teachers, coordinators, administrators; vocational rehabilitation personnel, and in some cases parents and students.

Key people from each region were asked to coordinate the effort by assembling the group and providing input concerning training needs, workshop objectives, and possible resources. This input proved to be a critical feature of the project.

\section{Content areas}

Two guidelines were critical: first, given the brief training period, no one workshop would address all 10 of the proposed content areas; second, selection of the content areas would be based on rankings by the regional planning committees.

\section{Planning}

The systems approach assured that each. step of the planning process was task analyzed, prescheduled, and written on a checklist or chart. These aids provided a vehicle for communication during meetings, allowed for systematic, on-going feedback throughout the year, and were later included in final reports. Similar aids were employed to facilitate effective local planning and to prepare the regional committee coordinators for their responsibilities.

\section{Time/cost features}

A travel agent assisted with the tedious and cumbersome tasks involved in arranging hotel accommodations, confirming costs, and verifying accessibility.

\section{Process}

This phase included all responsibilities required to present the training program. 


\section{Administration}

Execution of administrative responsibilities can either enhance or destroy the entire training effort. Several guidelines were operative: (a) record in writing all plans or changes and file these with a secretary; (b) conduct a few in-depth meetings to plan activities for several months; $(c)$ duplicate materials (brochures, evaluation forms) for each of the workshops in different colors; and (d) outline, schedule, and assign each administrative responsibility for each workshop. For example, one staff person was iden. tified as the "trouble shooter," assisting with problems related to room arrangements or travel reimbursement forms.

\section{Format}

The basic format for all the workshops was similar. Each provided an evening program featuring a keynote speaker from the State Department of Education who discussed current events (e.g., the new interagency agreement among vocational education, special education, and vocational rehabilitation) or special issues (e.g., bilingual education). The agenda of the following day included a continental breakfast, keynote speaker addressing a specific objective (e.g., sexism), small-group workshops, lunch, and panel discussions and discussion groups.

\section{Content}

At each workshop specific content areas were addressed in minisessions, and participants usually had the opportunity to select minises. sions to fit their individual needs. The presenters included teacher educators, teachers, consultants from local and intermediate agencies, parents, and handicapped individuals. Table 1 lists the 10 content areas, the number of workshops at which these content areas were addressed, the number of sessions presented, and sample titles of sessions: The number of topics and mini-sessions varied according to the recommendations of the local planning committee.

\section{Feedback}

A continuous feedback process was employed throughout the year. That is, staff collected and used performance information from each workshop in order to decide whether to maintain, modify, or discard aspects of the training program. For example, during the first workshop, several management problems emerged (e.g., registration delays), and the evaluation results reflected these difficulties. Consequently, adjustments were made in the procedures, and the data collected at the next workshop suggested improved performance. 


\section{Table 1}

Content areas, number of workshops, and sample sessions

\begin{tabular}{|c|c|c|c|}
\hline content areas & $\begin{array}{l}\text { number of } \\
\text { workshops }\end{array}$ & $\begin{array}{l}\text { number of } \\
\text { sessions }\end{array}$ & sample session titles \\
\hline Legislation, labels & 2 & 5 & $\begin{array}{l}\text { Special education laws } \\
\text { Deaf students }\end{array}$ \\
\hline $\begin{array}{l}\text { Attitudes related } \\
\text { to handicaps }\end{array}$ & 3 & 3 & $\begin{array}{l}\text { A personal view of being } \\
\text { handicapped }\end{array}$ \\
\hline $\begin{array}{l}\text { Classroom } \\
\text { interactions }\end{array}$ & 3 & 7 & $\begin{array}{l}\text { Communication patterns } \\
\text { in the classroom } \\
\text { The behavioral model }\end{array}$ \\
\hline $\begin{array}{l}\text { Specialized } \\
\text { materials }\end{array}$ & 4 & 5 & $\begin{array}{l}\text { Adapting vocational edu- } \\
\text { cation materials for the } \\
\text { handicapped }\end{array}$ \\
\hline Job placement & 5 & 5 & $\begin{array}{l}\text { Job placement procedures } \\
\text { Holding hands with CETA }\end{array}$ \\
\hline Support services & 3 & 3 & $\begin{array}{l}\text { Working with secondary } \\
\text { administrators } \\
\text { Working together- } \\
\text { Teachers and paraprofes- } \\
\text { sionals }\end{array}$ \\
\hline $\begin{array}{l}\text { Bilingual and } \\
\text { Multicultural }\end{array}$ & 4 & 5 & $\begin{array}{l}\text { Cultural differences in } \\
\text { vocational programs } \\
\text { Bilingual student concerns }\end{array}$ \\
\hline Sexism & 1 & 3 & $\begin{array}{l}\text { Sex role stereotyping } \\
\text { Sex equity }\end{array}$ \\
\hline Professional & 3 & 4 & $\begin{array}{l}\text { Job stress and burnout } \\
\text { Interpersonal communica. } \\
\text { tion }\end{array}$ \\
\hline Interagency & 3 & 3 & $\begin{array}{l}\text { Michigan's interagency } \\
\text { agreement }\end{array}$ \\
\hline
\end{tabular}

\section{Output}

This phase involved identification of outcomes and evaluation of the workshops by the participants.

\section{Outcomes}

A comparison of desired and actual outcomes indicates that the major goals and objectives of the inservice training project were accomplished (see Figure 1).

\section{Effectiveness}

The participants' views of workshop effectiveness were solicited at the six regional programs. Evaluation results and implications are discussed in the next section. 


\section{Figure 1}

Desired and actual outcome for state-wide, inservice project

desired outcomes

1. Provide state-wide inservice training to special needs personnel.

2. Address specific content areas and current issues.

3. Provide opportunities for interaction between personnel with different roles or disciplines.

4. Increase awareness about voca. tional/career programs for the handicapped.

5. Integrate information from the field to future university-based projects. actual outcomes

Eight workshops were presented, involving nearly 900 participants composed of teachers, coordinators, administrators, and paraprofessionals.

43 mini-sessions were offered by 29 presenters including teacher edu. cators, handicapped individuals, and school personnel.

The $11 / 2$-day format allowed for and encouraged this interaction. This aspect was reported as a strength.

A slide-tape presentation was completed illustrating available programs and services in the state.

Collaboration between field personnel and faculty in designing a combined vocation/special education master's sequence.

Integration of the needs assessment data into the competency-based degree program.

Refinement of management aids (charts, checklists) for use in future projects.

\section{EVALUATION}

\section{Questionnaires}

An 11-item questionnaire soliciting the participants' evaluation of the workshop was utilized. Seven of the items employed a 7-point, Likert-type scale, with 7 being the most positive (excellent, very beneficial) response and 1 the least positive (poor, inadequate) response. These questions related to evidence of organization, clarity of stated objectives, adequacy of workshop scope, perceived personal benefit as a result of attendance, and an estimate of overall satisfaction. Other items included open-ended questions requesting participants to list strong and weak features of the workshops as well as to make general comments.

A similar 8-item questionnaire was utilized to evaluate each minisession. 


\section{Results}

\section{Demographic information}

Of the 355 participants who completed the questionnaire, the vast majority were experienced (mean $=8$ years), employed full-time, and functioned as teachers, coordinators, or paraprofessionals in vocational and special needs rather than in special education (see Table 2).

\section{Overal evaluation}

In determining the level of overall satisfaction for the workshops, all 7 Likert-type items from the evaluation form were consolidated. The consolidated figure indicated that five of the six workshops were rated highly positive. At least half of the participants ranked these workshops as good or excellent, while not more than $4 \%$ of the participants found them unsatisfactory. The first workshop was ranked lowest, with only $12 \%$ of the responses 6 or greater and 10\% ranking the workshops as poor.

Because of the sharp difference between the first workshop and the 5 remaining workshops on the overall satisfaction dimension, a $t$-statistic was used to evaluate the difference between the means for all the other dimensions. The results indicate that Workshop I was rated significantly lower $(p<.001)$ on all dimensions across all workshops.

Each of the dimensions dealt with by the questions on the evaluation form was separately analyzed across workshops (see Table 3). The means for each of the items across workshops were above 5.26 on a 7-point scale. The "stronger" features of the workshops identified by the participants were the consultants and information, while the weaker aspects listed were the accommodations and the time constraints.

\section{Evaluation of mini-sessions}

The workshops involved 39 different mini-sessions. The number of participants in these sessions varied according to topics presented and participant interest.

To best illustrate the difference between the most and least positively viewed sessions, each question on the evaluation form was analyzed separately. A straightforward rank-ordering of means was established first and then the quartile divisions were established. Six sessions were ranked highest in terms of overall consideration (see Table 4). In descending order they were: teaching strategies to develop self-esteem (two sessions), bilingual student issues, job stress/burnout, deaf students, the handicapper experience, and support service for academic subjects.

\section{Discussion}

It is apparent from the workshop evaluation that the workshops were seen as effective and positively perceived.

The workshops ranked highest in general satisfaction were those in which two elements existed in the planning and process phases: staff 
Table 2

Participant characteristics summary table

$\begin{array}{lccc} & \text { male } & \text { female } & \text { total } \\ \text { Number of respondents } & 134 & 200 & 355^{*} \\ \text { Average years of teaching exp. } & 8.7 & 7.7 & 8.3 \\ \text { Range (years) } & 0-31 & 0-32 & 0-32 \\ \text { Position } & & & \\ \text { Voc education } & 64 & 67 & 131 \\ \text { Spec education } & 25 & 42 & 67 \\ \text { Spec needs } & 17 & 26 & 43 \\ \text { Other (e.g., parents, librarian, } & 48 & 90 & 138 \\ \quad \text { aide) } & & & \\ \text { Employment status } & & & 313^{*} \\ \text { Full-time } & 134 & 176 & 53^{*} \\ \text { Part-time } & 16 & 36 & 16 \\ \text { No response } & 0 & 16 & \end{array}$

-Some respondents did not check gender, so these totals are greater than the sum of males and fernales.

adherence to management guidelines and active participation by the planning committee. The workshop ranked lowest in general satisfaction was the one in which these two elements functioned least effectively.

In addition, the data indicate that the local committees predicted with some accuracy the needs and interests of their colleagues. Topics related to "affective" areas were suggested, and several of the mini-sessions ranked highest by participants involved personal (e.g., burn-out) or interpersonal topics (e.g., building self-esteem, experiences of a handicapper).

The dimension of the evaluation form that seems to most clearly affect the ratings is organization. As judged from written and verbal comments, this rating may be influenced by a variety of factors, some of which may be out of the immediate control of the workshop staff-a speaker's tardiness, inadequate noise insulation or lack of sufficient seating in an unexpectedly overcrowded session.

The number of available mini-sessions is one aspect under the control of workshop staff which may affect the participants' ratings of "workshop organization." The three workshops (II, III, IV) ranked highest in organization provided fewer alternatives (three to seven minisessions) than did the workshop ranked lowest in organization (IV), which offered the greatest number of alternatives (13 mini-sessions).

In sum, the evaluation results support the application of the systems approach to inservice training since the workshop ranked lowest was the one in which the guidelines used by staff and the local planning committees were least effectively followed. The system management approach serves to help in the organization and coherent presentation of a statewide series of workshops. From all indications, this management approach minimizes the potential hazards and difficulties in meshing the 


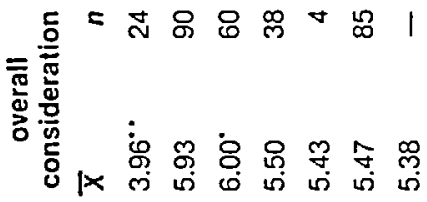

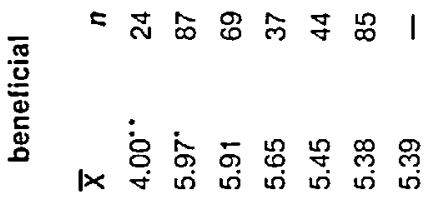

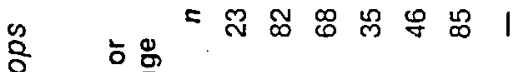

$$
\begin{aligned}
& \text { 竎 }
\end{aligned}
$$

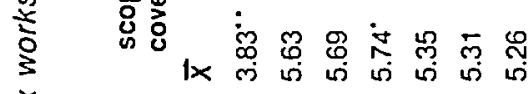

$$
\begin{aligned}
& \frac{x}{\omega}
\end{aligned}
$$

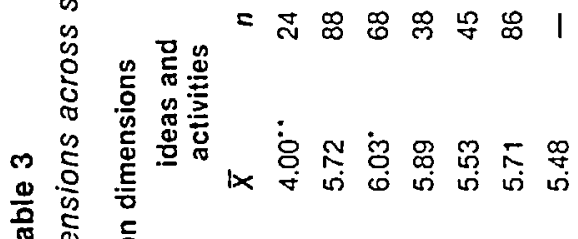

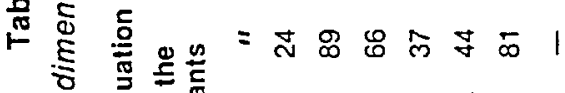

$$
\begin{aligned}
& \text { 离 }
\end{aligned}
$$

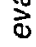

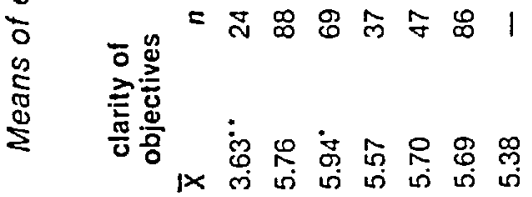

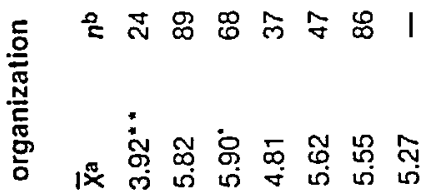

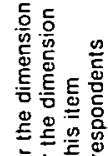

$$
\begin{aligned}
& \text { 흐는흥 }
\end{aligned}
$$

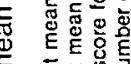

$$
\begin{aligned}
& \frac{0}{\frac{0}{0}} \\
& -=\equiv \geq>S \stackrel{\frac{0}{\sigma}}{0: 00}
\end{aligned}
$$


efforts of two departmental units while maximizing the successful and effective utilization of diverse resources.

\section{RECOMMENDATIONS}

Based on the application of a systems approach and the resulting project outcomes, the following recommendations are offered to inservice trainers.

\section{Input}

- Collaborate with those in related disciplines but allow ample time to establish lines of communication and working relationships.

- Insist that adequate time be provided to integrate needs assessment studies into the planning process.

- Establish and provide explicit guidelines for planning committees. Such committees should include school- and community-based representa. tives.

- Conduct a field test of the training or workshop so that management and organizational problems may be avoided.

- Consider the use of existing advisory committees from local or intermediate school districts and/or community organizations. This may reduce the time otherwise required to organize and train a planning committee.

\section{Process}

- Incorporate topics relating to awareness, attitudes, and interpersonal interactions into the training package.

- Insure that some sessions address specific needs according to different roles, disciplines, or disability areas.

- Invite presenters who have a practical orientation and who use tech. niques requiring active audience participation (e.g., simulations, demonstrations). Include some presenters who are handicapped themselves.

- Obtain information about hotel service and management (food, space, and promptness) from previous clients.

\section{Feedback}

- Assume that some problems will develop and prearrange methods for monitoring and solving them.

- Use charts and checklists as the basis for conference agendas and dis. cussions.

\section{Output}

- Stress the confidentiality and importance of the evaluation procedures, underscoring the need for specificity. 
- Designate funds for a systematic follow-up to ascertain the impact of training on participants and/or the handicapped students they serve.

\section{SUMMARY}

Inservice training in the area of career and vocational education for personnel serving handicapped students is a necessity. Providing relevant and comprehensive training, however, is a complex task, requiring a multi. disciplinary approach and access to the resources of schools and agencies throughout a state.

The positive evaluation of this joint endeavor between vocational and special education programs illustrates that such difficult issues can be dealt with. The adaptation of a systems approach, including the impact of a regional planning committee and collaboration between vocational and special education, is advocated as a way of designing and delivering inservice training in a timely and cost-effective manner.

\section{REFERENCES}

Berman, P., \& McLaughlin, M.W. Implementation of educational innovation. Education Forum, 1976, 40, 344-370.

Brown, W. Systems, boundaries, and information flow. Acadamy of Management Journal, 1966, 9, 318.

Heller, H.W., \& Schilit, J. Career education for the handicapped: Directions for the future. Career Development for Exceptional Individuals, 1979, 2, 91-95.

Mockler, R.J. Information systems for management. Columbus, Ohio: Charles E. Merrill Publishing, 1974.

Moorman, J.W. Vocational education for the handicapped: A study of attitudes. The Journal for Vocational Special Needs, 1980, 2, 22.

Wiener, N. The human use of human beings: Cybernetics and society. Boston: Houghton Mifflin, 1950.

Geraldine Markel, Special Education; Ella Bowen, Occupational Education; Gregory Kasza, Doctoral Student, Education and Psychology; and Sherry Bell, Doctoral Student, Occupational Education; all, School of Education, University of Michigan, Ann Arbor, MI 48109.

\section{career quote}

"Fighting job discrimination by nature is very frustrating work. At this point, we're inured to frustration. We are not going to shut up."

Leslie Milk 